when it becomes economically necessary for our marginal lands to be resettled, but at present the population trend is still towards the town and away from the country.

One last point-Hart appears to accept without question that Britain's population will go on expanding rapidly. He does not realize, or will not acknowledge, that one of the best ways to become self-sufficient is to restrict our population growth. This may seem to be as much crying for the moon as is his vision of a wellmanaged vista of productive uplands, but in twenty years' time both may be well on the way to fulfilment, from necessity rather than choice. S. R. J. WoodeLL

\section{LANGUAGE IN ACTION}

\section{Words, Meanings, and Messages}

Theory and Experiments in Psycholinguisties. Ragnar Rommetveit. Pp. viii +328. (Academic Press: New York and London; Universitetsforlaget: Oslo, 1968.) n.p.

"Existing fraginents of psycholinguistic theory and data resemble bricks in a puzzle, the solution of which is as yet unknown. As a consequence, we are left with a multitude of fragmentary insights and with a challenge to bring such fragments together into a theoretically coherent picture of human language in action. This book is a response to such a challenge." Judged in terms of this-the author's avowed aim in writing it--Professor Rommetveit's book must be accounted a failure. But, then, given such terms, this is hardly surprising. "A theoretically coherent picture of human language in action" may, perhaps, serve as a general (in fact, a far too general) description of what psycholinguists hope one day to produce. Very few of them seriously believe that it is about to emerge. The trouble, as far as Rommetveit's summary of recent work in psycholinguistics is concerned, is that judged by this impossibly high standard much of its interest and significanco tends to be obscured. This tendency is inercased by the large amount of space Rommetveit gives up to very general discussions of areas of research which most psycholinguists are content for the moment to leave unexplored-in particular those covering the relationship between speech and context. It is, of course, perfectly true that nearly every time we speak what we actually say is to some cxtent influenced by factors in the situation in which we find ourselves. But no one, and this includes Rommetveit, has the first idea how to go about constructing a systematic account of these relationships. Nor is it the case, as Rommetveit sometimes seems to be implying, that most contemporary psycholinguists are unaware of the phenomenon. It is simply that in omitting consideration of these factors at this time they are deliberately following out a research programme which puts the study of what language is before the study of how we use it.

The reasons for concentrating linguistic studies on the discovery of the formal structure of language were clearly set out by Noam Chomsky in his review of B. F. Skinner's book Verbal Behavior (Language, 35; 1957), in which he also demonstrated that stimulus-response models were quite inadequate to account for linguistic behaviour in general and the structure of linguistic events in particular. In the same year, Chomsky published a formal description of language structure mecting reasonably strong conditions of adequacy (Syntactic Structures (Hague: Mouton, 1957). Since that time? considerable advances have been made by Chomsky and other linguists in refining and extending models of language structure. The speed of this advance has caused problems for psycholinguists who have found themselves constantly in danger of testing hypotheses which the linguists have alrcady abandoned. At the same time it is very easy to find structures that linguists have doalt with inadequately or not at all. Rommetveit makes both these points, but ho also makes eriticisms of this work of a fundamental nature. On page 43 in a discussion of the relationship between what he terms "message" and "utterance", he argues that the existence of synonymous utterances indicates that "The message is thus not of a linguistic nature". Again on page 83 he talks of "criteria of cogni. tive synonymy" as being "extra-linguistic considerations of a psychological nature". It is difficult to be sure what it is Rommetveit means by these and similar remarks scattered throughout the book, but it seems that he is claiming that no relationship exists between the linguist's abstract accounts of the meaning of a sentence and our understanding of it. If this is in fact what Rommetveit is claiming, then it is a very important claim indeed, because it amounts to saying that much of the psycholinguistic research done over the past ten years is groundless. It is all the more puzzling, therefore, that Rommetveit nowhere makes these points clearly and never tries to substantiate them. JAMES P'eter Thorne

\section{ELUSIVE FLIES}

\section{Ecology of Insect Vector Populations}

By R. C. Muirhead-Thomson. Pp. vii +174 . (Academic Press: London and New York, (October 1968.) $50 s$; \$9.50.

THis book provides a useful review of the various trapping methods used in the study of the insect vectors of (mainly) human diseases. The words "ecology" and "populations" in the title are misleading because the body of the book concentrates almost entirely on a comparison between different methods of capturing or sampling the adult insects. There are chapters on tsetse flies which transmit trypanosomiasis, the anopheline mosquitoes implicated in malaria, the culicines concerned with filariasis, the simuliids which carry onchocercosis, and the fleas which are involved as vectors of plague from rodents to man and vectors of myxomatosis among rabbits. All these insect vectors have complex life histories, with larval stages whose environmental needs are quite different from the blood sucking adults. An account of the ecology of such insects should include a detailed consideration of these stages, which is lacking in this book. Although an assessment of the adult population of the vector is important, the author makes the defeatist assertion that it is "never possible in nature to refer trap figures to a known population". Yet methods which have largely overcome this difficulty for tsetse flies and other insects are discussed briefly in ehapter eight. These methods are a refinement of the Lincoln. Index method and involve marking and recapture. The basic difficulties are inherent in the use of traps which rely on visual or chemical attraction. This varies with the physiological state of the unsect so that different sorts of trap capture different proportions in relation to age and sex. The area from which they come is hard to define.

In the last chapter, headed "Summary and Discussion", the author mentions a meeting held in (Keneva in 1966 where mosquito ecology was discussed. There it was agreed that "there was still a serious lack of quantitative information about many aspects of mosquito ecology", and that "better methods for the measurement of numbers of mosquitoes would provide a better understanding of population dynamies".

Life-table studies, which form no part of this book, were also recommended. When they are available for the host, the parasite and the vector, we shall be in a position for the next big advance in the understanding of these complex interrelationships by the use of a population model based on measured values. Clearly there is a very long way to go before a satisfactory model can be made for even the best known interactions. The question needs to 
be asked why progress has been so slow, considering that the pioneer of population dynamics was Sir Ronald Ross. In chapter five of his book, The Prevention of Malaria (London, 1910), Ross used a population model which expressed in algebraic terms the way in which infection rate was related to the properties of the human and mosquito populations, represented by six symbols. Recent developments of Ross's ideas will be found in The Epidemiology and Control of Malaria by G. MacDonald (London, 1957). This promising line is not followed here. Neither Ross nor MacDonald appears in the bibliography and no attempt is made to assess even one of Ross's six factors.

Ecologists interested in population dynamies will be disappointed in this book. Those concerned with the deployment of effort in medical entomology should consider whether the present strategy is likely to provide an understanding of these ecological problems.

G. C. VARLEY

\section{PALAEARCTIC DRAGONFLIES}

\section{Les Odonates de l'Europe Occidentale, du Nord de l'Afrique et des lles Atlantiques}

By P. Aguesse. (Faune de l'Europe et du Bassin Mediterranéen, 4.) Pp. 255. (Masson et Cie: Paris, 1968.) 80 francs.

This book is one of a series devoted to the systematics of animal taxa in the western Palaearctic Region. Publication is sponsored by the Centre Nationale de la Recherche scientifique. This volume, on dragonflies, encompasses western Europe (excluding Denmark, Poland, Romania and Yugoslavia), north-western Africa (Tunisia, Algeria and Moroceo) and Madeira, the Azores and the Canaries. Mediterranean countries east of Italy or Tunisia are not included.

The book is lavishly produced. It contains four beautiful colour plates and a half-tone sketch by the noted illustrator and naturalist P.-A. Robert.

The text is arranged in two parts: general and systematic. The first deals with the morphology and bionomics of dragonflies as a group. It presents, in 67 pages, a selection of published information, and includes some unpublished findings known to the author. Matorial is not critically reported; terminology is not always consistent; authors are sometimes misquoted; and the source of a specific fact can seldom be traced unequivocally. To some readers the most interesting part of this general section will be that devoted to seasonal regulation because of the detailed treatment given to little-known work by Schaller and the author on dimorphic growth rate in Aeshnidae. These findings are likely to have considerable influence on future work in this field. Here as elsewhere, however, the author's treatment of his subject fails to be authoritative because other relevant studies (for example, those by Lutz and Jenner) are omitted and their implications are not taken into account.

The second, systematic part, occupying about two thirds of the book, contains separate sections on adults and larvae. It combines taxonomic information for European species, which are well known, with that for the north-western African species. This part is adequate and useful, although some pertinent references are omitted. Keys and accompanying illustrations by the author are clear, and easy to find and use. Distribution maps are given for some species.

There is a bibliography of some 300 titles and an index to the 40 genera and 109 species treated. The value of the extensive bibliography is reduced by the omission of certain key references (including several cited in the text), and by the fact that many entries lack page numbers. Mention of a reference in the bibliography does not mean that its contents have been eited, or allowed for, in the text.

People requiring a manual, in one cover, for western Palaearctic Odonata will find the systematic part of this book useful. Philit S. Corbet

\section{LYMPHOCYTE STIMULATION}

\section{Lymphocyte Stimulation}

By N. R. Ling. Pp. 290. (North Holland: Amsterdam, 1968.) $117 s$.

IT is perhaps hardly surprising that many experimental observations are neglected until their real significance can be evaluated against an appropriate backcloth. Such was the case with immunological tolerance, the consequences of which were known to experimental embryologists long before its existence as an important biological phenomenon had been demonstrated; and, as Dr Ling points out in his scholarly book, the same could be said of lymphocyte stimulation. Thus Maximow at the turn of the century described the occurrence of blast cells in inflammatory exudates and he contended that at least some of them were derived from blood lymphocytes, and with the benefit of hindsight it is clear that Bloom's later descriptions of cell transformations referred to the development of blast cells from lymphocytes.

It was, however, the discovery in the middle fifties of the plant agglutinins (or lectins)-notable among them those of the red kidney bean Phaseolus vulgaris-and the realization that lymphocytes play a vital part in graft rejection and in delayed hypersensitivity that set the stage for carefully conducted and controlled in vitro experiments on lymphocyte stimulation. Among the morphological and biochemical changes that occur when lymphocytes are cultured in the presence of phytohaem. agglutinins (PHA) or other stimuli are cell and nuclear enlargement, the development of an ample cytoplasm, the appearance of numerous free ribosomes, greater pinocytotic activity, increased RNA and subsequently DNA synthesis, and finally cell division. Ling is undoubtedly justified in giving pride of place to PHA, which has been used so extensively in the study of lymphocyte stimulation, but sections of the book are also devoted to the stimulatory effects of tuberculin products, staphylococcal filtrate, smallpox vaccine, heterologous antibodies and cell contact. Perhaps least satisfactory is his treatment of allogeneic inhibition which, although it is concerned with cytotoxicity, deserves closer scrutiny in the context of lymphocyte stimulation.

Ling makes the reader fully aware of the complex technology that has been applied to the study of lymphocytes, and his chapter on lymphocyte culture will be most valuable to those embarking on work or already working in this field. What also emerges is that in many respects we are still remarkably ignorant of the immunological status of cells stimulated in vitro; the literature on the presence of specific immunoglobulins is still somewhat confused, and it would seem that little is known about the immunological performance of stimulated lymphocytes. On the question of how stimulation comes about there is room for argument too, but Ling favours the presence of specific cellular receptors which bind the stimulant rather than agglutination per se, or nutritional factors, or micro-injury. If this is so, lymphocyte stimulation, which in any one culture occurs in a high proportion of cells, would not be easy to square with the clonal selection hypothesis.

This timely book, which is written with great lucidity, will be most welcome to those working in the field. But because it encompasses so many facets of the subjectbiological, biochemical, immunological and clinical-its appeal will be not only to those interested in lymphocytes but to cell biologists of every hue. LesLie Brent 